\title{
Retroperitoneal hematoma after coil embolization of cerebral aneurysm -A case report-
}

\author{
Hye Young Kim², Mi-Hyun Kim ${ }^{1}$, Seung Hye Jung ${ }^{1}$, Junghee Ryu ${ }^{1}$, Young-Tae Jeon ${ }^{1}$, Hyo-Seok Na ${ }^{1}$, \\ and Jin-Young Hwang ${ }^{1}$
}

Department of Anesthesiology and Pain Medicine, ${ }^{1}$ Seoul National University Bundang Hospital, Seongnam, ${ }^{2}$ Seoul National University College of Medicine, Seoul, Korea

We present the case of a 57 -year-old man who developed retroperitoneal hemorrhage due to unintentional arterial puncture during femoral artery cannulation for Guglielmi detachable coil embolization. On emergence from anesthesia, he developed severe hypotension. Computed tomographic angiogram of the abdomen showed retroperitoneal hematomas around the urinary bladder, liver, and spleen. Because femoral artery cannulation is a common procedure for intravascular embolization in neuroradiologic procedures, Clinicians should be aware of the development of severe hematomas as a consequence of femoral artery puncture. (Korean J Anesthesiol 2010; 59: S187-S190)

Key Words: Cerebral aneurysm, GDC embolization, Intervention, Retroperitoneal hemorrhage.

In many centers, endovascular treatment is considered the first-choice treatment for $60-70 \%$ of all ruptured aneurysms. However, many complications are associated with endovascular procedures, such as aneurysmal rupture, thromboembolism, bleeding, retroperitoneal hematoma, and other vascular complications [1].

Retroperitoneal hematoma is a rare clinical entity with variable causes; its incidence is increasing mainly because of complications related to interventional procedures. Currently, it is described as a complication of femoral artery catheterization and pelvic or lumbar trauma [1].

Retroperitoneal hematoma is a cause of significant morbidity [2]. Unlike other bleeding sites, the retroperitoneum can harbor a large volume of blood, which remains undetected until hypovolemia occurs. This leads to delayed diagnosis, increased morbidity, and a potentially fatal result [3].

We present a case of retroperitoneal bleeding as a consequence of femoral artery cannulation for Guglielmi detachable coil (GDC; Boston Scientific, Cork, Ireland) embolization in a patient with recanalized cerebral aneurysm.

Received: March 23, 2010. Revised: 1st, April 23, 2010; 2nd, May 24, 2010. Accepted: June 16, 2010.

Corresponding author: Mi-Hyun Kim, M.D., Department of Anesthesiology and Pain Medicine, Seoul National University Bundang Hospital, Gumi-dong, Bundang-gu, Seongnam 463-707, Korea. Tel: 82-31-787-7496, Fax: 82-31-787-4063, E-mail: ohara@snu.ac.kr (c) This is an open-access article distributed under the terms of the Creative Commons Attribution Non-Commercial License (http:// creativecommons.org/licenses/by-nc/3.0/), which permits unrestricted non-commercial use, distribution, and reproduction in any medium, provided the original work is properly cited. 


\section{Case Report}

A 57-year-old man (height, $170 \mathrm{~cm}$; weight, $67 \mathrm{~kg}$ ) diagnosed with recanalized cerebral aneurysm of the left anterior communicating artery was scheduled to undergo GDC embolization. He had undergone the same procedure a month ago. He had no other medical condition of note. His Glasgow Coma Scale score was 12 of 15 (eye opening, 3; motor response, 5 ; verbal response, 4). No other focal neurological deficit was observed. His coagulation profile was normal, and his hemoglobin level was $11.8 \mathrm{~g} / \mathrm{dl}$.

The preinduction blood pressure and heart rate were 132/83 $\mathrm{mmHg}$ and 53 beats/min, respectively. After anesthetic induction of $4 \mu \mathrm{g} / \mathrm{ml}$ (effect-site concentration) propofol and $2 \mathrm{ng} / \mathrm{ml}$ remifentanil by target-controlled infusion (TCI) using an Orchestra ${ }^{\circledR}$ infusion pump system (Fresenius Kabi, Brezins, France), $50 \mathrm{mg}$ rocuronium was administered to facilitate tracheal intubation.

During embolization, the blood pressure and heart rate were maintained at $102-130 / 68-74 \mathrm{mmHg}$ and $50-60$ beats/ min, respectively, with a TCI of $3 \mu \mathrm{g} / \mathrm{ml}$ propofol and $2 \mathrm{ng} / \mathrm{ml}$ remifentanil. The right femoral artery was cannulated with a 6 Fr introducer sheath, and 3,000 IU heparin was administered intravenously to prevent thromboembolism. The embolization was successfully performed in $1 \mathrm{~h} 30 \mathrm{~min}$. After the sheath for the GDC embolization procedure was removed, the femoral puncture site was closed with Perclose ${ }^{\circledR}$, Angioseal ${ }^{\circledR}$, and Safe Guard $^{\circledR}$.

After the anesthetics were discontinued, $0.4 \mathrm{mg}$ glycopyrrolate and $1.5 \mathrm{mg}$ neostigmine were administered for reversal of muscle relaxation. During emergence from anesthesia, with the endotracheal tube still in place, his blood pressure suddenly

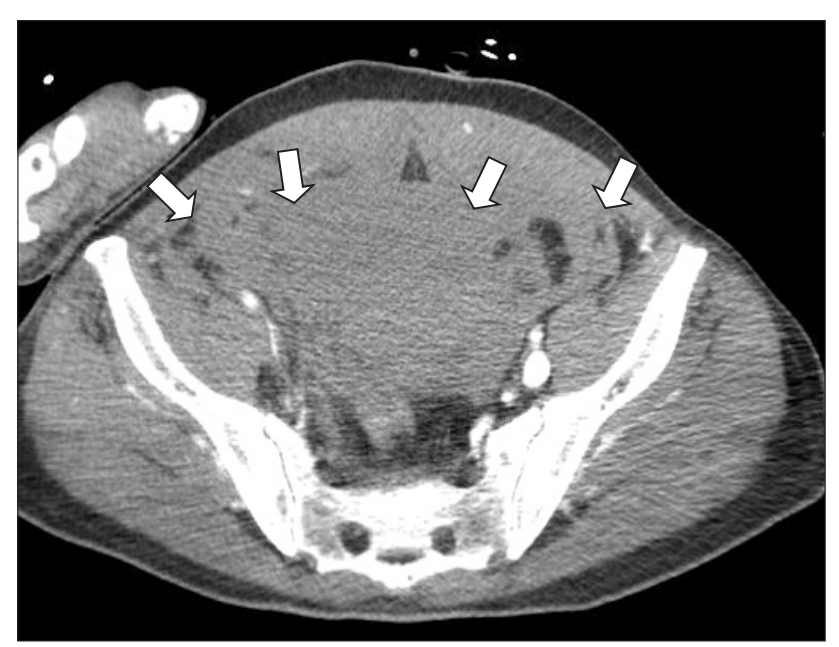

Fig. 1. Abdominal CT angiogram revealing retroperitoneal hemorrhage in the perivesical space (arrows). dropped to $51 / 23 \mathrm{mmHg}$, and his heart rate increased to 103 beats/min. Then, $10 \mathrm{mg}$ ephedrine and $500 \mathrm{ml}$ hydroxyethyl starch were administered intravenously. The blood pressure increased transiently to $72 / 53 \mathrm{mmHg}$, but dropped again. For continuous monitoring of blood pressure, the right radial artery was cannulated with a $20-\mathrm{G}$ IV catheter. The patient could breathe spontaneously, but his conjunctiva was very anemic and his abdomen was rigid. His hemoglobin and hematocrit levels were $5.9 \mathrm{~g} / \mathrm{dl}$ and $17.8 \%$, respectively. The results of other laboratory tests were as follows: Na level, $146 \mathrm{mmol} / \mathrm{L}$; K level, $3.9 \mathrm{mmol} / \mathrm{L}$; pH, 7.29; $\mathrm{pCO}_{2}, 41.3 \mathrm{mmHg} ; \mathrm{pO}_{2}, 416.5$ mmHg; base excess, $-6.8 \mathrm{mmol} / \mathrm{L}$; creatine kinase-muscle and brain fraction (CK-MB) level, $0.2 \mathrm{IU} / \mathrm{L}$; and troponin level, $<0.01 \mathrm{ng} / \mathrm{ml}$. No bleeding focus was detected at the femoral puncture site. Abdominal sonography was performed to screen for intraperitoneal hematomas, but no specific finding was obtained. Computed tomographic (CT) angiogram of the abdomen showed hematomas around the urinary bladder, liver, and spleen (Fig. 1 and 2); pseudoaneurysm between the right femoral artery and right inferior epigastric artery; and active extravasation from the origin of the right inferior epigastric artery (Fig. 3). The self-expandable stent for embolization of the bleeding site was inserted through the contralateral femoral artery (Fig. 4). The bleeding was successfully controlled after stent insertion.

During the procedure, the blood pressure and heart rate were maintained at $110-118 / 67-72 \mathrm{mmHg}$ and $112-123$ beats/ min, respectively. The patient was under anesthesia for $4 \mathrm{~h} 20$ min, during which $3,000 \mathrm{ml}$ crystalloid, 1,000 ml colloid, and 2 units of packed RBCs were administered; his urine output was $980 \mathrm{ml}$. After the procedure the patient was transferred to the intensive care unit.

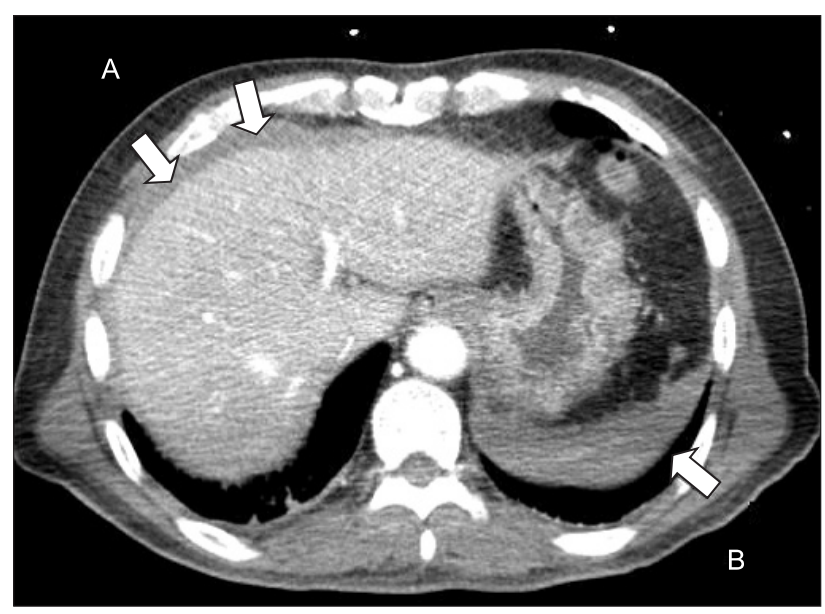

Fig. 2. Transectional view of abdominal CT angiogram shows hemoperitoneum. The arrows indicate hemorrhage in perihepatic (A) and perisplenic space (B). 


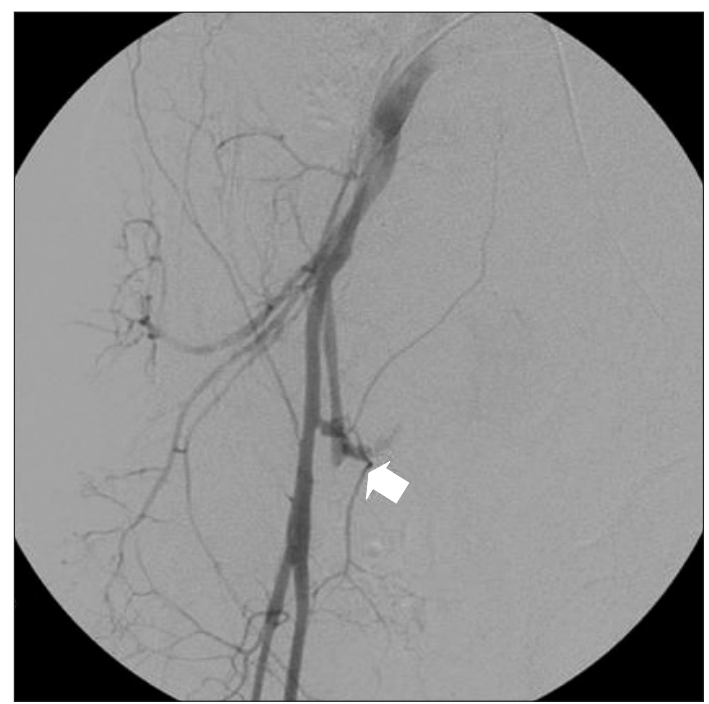

Fig. 3. Angiogram shows pseudoaneurysm with active extravasation at the origin of the right inferior epigastric artery (arrow).

He was extubated $9 \mathrm{~h} 30$ min after the induction of anesthesia and was transfused with 3 additional units of packed RBCs. Two days later, he was transferred to the general ward. The abdominal CT scan at 7 days after the procedure showed a decrease in the size of the retroperitoneal hematoma. The patient was discharged 2 months later without any sequelae.

\section{Discussion}

We present a case of retroperitoneal hemorrhage caused by unintentional arterial puncture during femoral artery cannulation. A retroperitoneal hematoma may be associated with femoral artery puncture irrespective of whether a closure device is used after the intervention [4]. It can be caused by an inadvertent puncture of the posterior wall of the femoral or iliac artery during cannulation.

Multiple attempts to puncture the femoral artery or puncture points high above the inguinal ligament of the femoral artery may result in occult retroperitoneal bleeding $[3,5]$. These reports probably explain the hemorrhage in our case, since multiple attempts were made to puncture the femoral artery, and the femoral artery was punctured above the level of the inguinal crease.

Even uncontrolled retroperitoneal bleeding may show initial clinical signs that are very subtle, leading to delayed diagnosis. Relative hypotension and mild tachycardia that transiently improve with the administration of fluids should alert clinicians to the possibility of retroperitoneal hematoma, and warrant further investigation [6]. The initial symptoms may progress to hemodynamic instability and arterial collapse. Ultrasonography of the abdomen and pelvis may aid in the

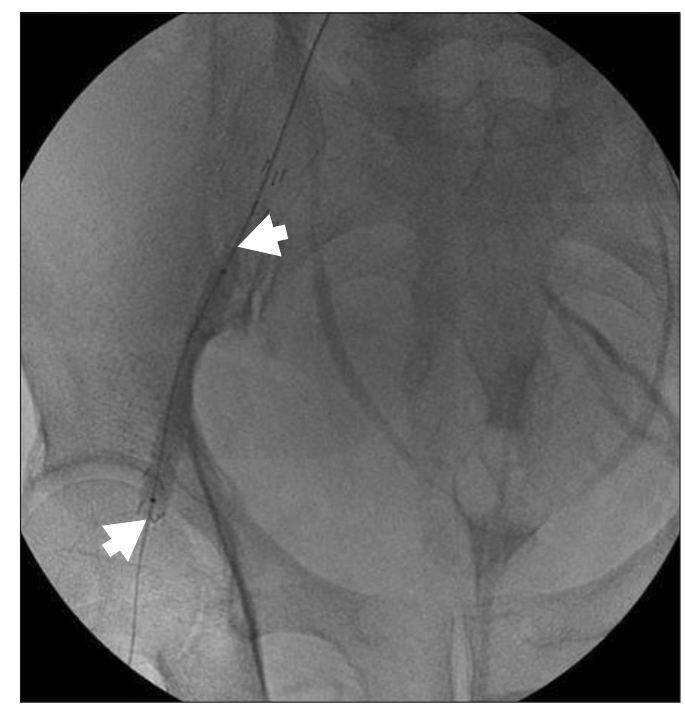

Fig. 4. Stent graft placement for femoral arterial bleeding. The arrows indicate the self expandable stent placed in the right femoral artery.

detection of hematomas, but it cannot help determine the cause $[2,7]$. Free fluid or blood in the retroperitoneum often flows into the abdominal or pelvic cavity, which can be detected as free abdominal fluid on an ultrasound scan [8]. In our case, however, no abdominal fluid was identified on the sonogram. CT is a noninvasive, rapid, and highly sensitive imaging method [9], and a CT angiogram may show the site of bleeding along with the contrast outside the vessels, an indication for urgent treatment. Active bleeding can be seen as extravasation of contrast material [10]; this was observed in our case as well. If the patient is hemodynamically stable with no evidence of ongoing bleeding, conservative management, such as careful monitoring, fluid resuscitation, blood transfusion, and normalization of coagulation factors, is recommended. Embolization is rapidly replacing open surgery in the treatment of retroperitoneal bleeding caused by iatrogenic iliofemoral vessel injuries [4]. Open surgery is opted if the patient remains unstable despite adequate fluid and blood product resuscitation, or if interventional radiology is unsuccessful or unavailable [1].

In our patient, the vital signs were stable during GDC embolization. We assumed that the sheath cannulated into the femoral artery might block the bleeding focus at the site of the right inferior epigastric artery. The initial clinical sign of hemorrhage in this case was abrupt hypotension and tachycardia. The CT scan performed immediately aided in the timely diagnosis of retroperitoneal hematoma, and thereafter, the conditions were appropriately managed by both anesthesiologists and neuroradiologists.

In conclusion, anesthesiologists should be aware of the occurrence of retroperitoneal hemorrhage as a consequence of interventional procedures such as femoral arterial puncture. 
When On clinical suspicion, immediate imaging should be performed to determine the site and extent of the hematoma; fluid and blood product resuscitation is also essential. The severity of retroperitoneal hemorrhage in our patient suggests the need for prompt intervention in such cases.

\section{References}

1. Bradac GB, Bergui M, Stura G, Fontanella M, Daniele D, Gozzoli $\mathrm{L}$, et al. Periprocedural morbidity and mortality by endovascular treatment of cerebral aneurysms with GDC: a retrospective 12-year experience of a single center. Neurosurg Rev 2007; 30: 117-26.

2. Merrick HW, Zeiss J, Woldenberg LS. Percutaneous decompression for femoral neuropathy secondary to heparin-induced retroperitoneal hematoma: case report and review of the literature. Am Surg 1991; 57: 706-11.

3. Farouque HM, Tremmel JA, Raissi Shabari F, Aggarwal M, Fearon WF, Ng MK, et al. Risk factors for the development of retroperitoneal hematoma after percutaneous coronary intervention in the era of glycoprotein IIb/IIIa inhibitors and vascular closure devices. J Am Coll Cardiol 2005; 45: 363-8.

4. Lubavin BV. Retroperitoneal hematoma as a complication of coronary angiography and stenting. Am J Emerg Med 2004; 22: 236-8.

5. Grier D, Hartnell G. Percutaneous femoral artery puncture: practice and anatomy. Br J Radiol 1990; 63: 602-4.

6. Money SR, Lepore MR. Iatrogenic vascular trauma. In: Vascular Trauma, 2nd ed. Edited by Rich NM, Mattox KL, Hirshberg A: Philadelphia, PA, Elsvier Saunders Publishers. 2004, pp 427-42.

7. Silverstein A. Neuropathy in hemophilia. JAMA 1964; 190: 554-5.

8. Ruchholtz S, Waydhas C, Lewan U, Pehle B, Taeger G, Kühne C, et al. Free abdominal fluid on ultrasound in unstable pelvic ring fracture: is laparotomy always necessary? J Trauma 2004; 57: 27887.

9. Lindner A, Zierz S. Images in clinical medicine. Retroperitoneal hemorrhage. N Engl J Med 2001; 344: 348.

10. Becker CD, Mentha G, Schmidlin F, Terrier F. Blunt abdominal trauma in adults: role of CT in the diagnosis and management of visceral injuries. Part 2: gastrointestinal tract and retroperitoneal organs. Eur Radiol 1998; 8: 772-80. 